\title{
Hilos y política. Visualidad en bordados como registro histórico del estallido social chileno de 2019
}

Katherine Verónica Suil Aravena ${ }^{(1)}$ y Pamela Petruska Gatica Ramírez ${ }^{(2)}$

Resumen: Este artículo presenta el bordado como artefacto cultural femenino, entendiendo que el bordado concebido como una actividad femenina menor se ha ido transformando, pudiendo ser un acto político, para el activismo y la memoria. Es en donde el diseño se puede articular como un actor cuya experiencia se hace vivencial además de productora de artefactos de uso.

A través de la revisión teórica se enmarca el proyecto de un relato textil realizado en el contexto del denominado estallido social chileno acontecido en octubre de 2019.

El proyecto constituye una bitácora a través de bordados elaborados durante el periodo de octubre del 2019 y marzo del 2020, para ser exhibido en plataformas digitales.

Palabras clave: Bordado - cultura - diseño - memorias - mujeres - política.

[Resúmenes en inglés y portugués en la página 212]

${ }^{(1)}$ Licenciada en Diseño Gráfico. Universidad de Chile. katherine.suil@ug.uchile.cl

(2) Doctora en Investigación en Diseño por la Universidad de Barcelona. Diseñadora en Comunicación Visual. Investigadora en las áreas del diseño y afecto, política y género. Profesora asistente del Departamento de Diseño, FAU, Universidad de Chile. pamela.gatica@ uchile.cl

\section{El bordado como artefacto cultural femenino}

El género femenino, y la mujer, han sido desplazados en la historiografía a papeles secundarios, por lo general solo algunas han sido destacadas por romper totalmente el rol que se les ha impuesto o han cumplido a cabalidad los ideales femeninos de su época. En el campo de las artes, las mujeres que lograron dejar su huella en la historia no eran ajenas a poseer privilegios que para otras mujeres no eran accesibles, como la educación, un estatus social alto y los recursos económicos, que permitieron su desenvolvimiento en las 
artes u otros (Nochlin, 2018), dejando un universo de mujeres que han sido olvidadas e invisibilizadas y su legado material artístico ha sido desvalorado.

El artefacto de memoria es una escenificación de las memorias subterráneas que es susceptible de ser descifrada. Pollak (2006) define las memorias subterráneas, que se expresan de manera material en los artefactos de memoria, los cuales pueden ser performances, monumentos, paredes pintadas, piedras, tejidos, canciones, etcétera; que buscan registrar y/o llamar la atención sobre alguna violencia que tuvieron que padecer.

Isava (2009), al hablar de artefactos culturales, en los cuales es posible insertar los artefactos de memoria, señala que la diferenciación de estos versus los artefactos cotidianos, serían su espesor significante influenciado por las ideas de Heidegger (1980) respecto a la esencia de la obra de arte. Así es como habla de un proceso de asignación de significado a través de la puesta en obra de la cultura, lo cual otorga al artefacto cultural de redes de significación y las patenta de manera que puedan escenificar una inscripción susceptible a ser leída, analizada e interpretada.

Ahora bien, es importante destacar el rol de la "crisis" dentro de la producción de memorias y su respectiva escenificación en artefactos, puesto que tanto Pollak (2006) como Lifschitz y Arenas (2012) analizan la memoria desde sucesos desencadenantes trágicos, marcados por la violencia y la represión, esto es debido a que la creación de memorias subterráneas está marcada por el silenciamiento de quienes la portan, de una especie de impotencia de expresión que lo recluye a este nivel invisible, que provoca que se transmita en núcleos pequeños como la familia, comunidades íntimas, grupos de ayuda, etc. Así mismo, sus manifestaciones como artefactos de memoria están marcadas por la subordinación y la victimización que llevan a los individuos a encontrar un medio de expresión ante la impotencia del silencio.

Por una parte, entendemos que los momentos de crisis humanitarias provocan la producción de memorias subterráneas y que al mismo tiempo estás proliferan en manifestaciones como artefactos de memoria, pero también existe la posibilidad de que la manifestación de las memorias subterráneas salga a la luz o sea un desencadenante de un momento de crisis.

Pollak (2006) señalaba que el registro histórico “oficial” provenía de una especie de encuadramiento de memoria, el cual es un acuerdo común que sirve de guía sobre los sucesos importantes para la humanidad. Sin embargo, este relato puede llegar a ser influenciado por entes dominantes para sus propios propósitos, proceso al que llama reconstrucción política de la memoria, la que puede devenir en una falsificación que a su vez repercutirá fuertemente en las memorias individuales, provocando un descalce entre la historia oficial y las memorias individuales, y que tarde o temprano terminarán desencadenando los gritos de la contraviolencia, que vendría a ser la manifestación violenta de parte de los dominados productos del odio y resentimiento acumulado que desencadenará un reajuste de memoria.

Es por ello que los momentos de crisis son un elemento fundamental, puesto que pueden ser provocados a partir de los desajustes que traen consigo las memorias subterráneas y al mismo tiempo son los productores de nuevas memorias y provocan la proliferación de sus manifestaciones como artefactos de memoria. 


\section{El bordado y la lucha feminista}

En The subversive Stitches: embroidery and the making of the feminine (1984), Roszika Parker construye un recorrido del proceso histórico de la conformación de la idea de feminidad y su vinculación con el bordado desde la Edad Media hasta el siglo XX, planteando cómo el bordado (y el arte en general) está implicado en la creación de la feminidad y, al mismo tiempo, los ideales femeninos determinaban el estilo y la iconografía de los bordados.

La exclusión de la mujer hacia la vida doméstica plantearía la idea de que las mujeres "eran seleccionadas naturalmente para la costura, genéticamente programadas para bordar" (Parker, 1984, p. 64). Durante el Renacimiento el bordado adquirió un papel importante en el establecimiento de lo femenino, promoviendo los valores del hombre renacentista: combinaba la humildad de la costura (needlework) con el lujo de la confección (stitchery). Connotaba la opulencia y la obediencia, ya que además por la naturaleza del mismo, la mujer se obligaba a quedarse largas horas en casa, retirada y en privado. Así es como la costura en el siglo XVII se volvió un pilar de la educación de la mujer.

Roszika Parker nos permite comprender que el bordado parte desde una creación sumisa y silenciosa que prosigue a un medio de empoderamiento de la mujer, señalando que:

El bordado se sigue identificando con la feminidad, pero el contexto ha cambiado. Las mujeres desafían los límites de la feminidad establecida previamente por lo masculino, en general las mujeres ya no bordan como un gesto de esposas o labores domésticas (Parker, 1984, p. 215).

Siguiendo la huella de Parker, Clare Hunter en Threads of Life: A History of the World Through the Eye of a Needle (2019) relata de manera autobiográfica diferentes encuentros que tuvo con textiles que relataban historias, desde los medievales que cuentan y resguardan historias con varios niveles de profundidad a partir de la sucesión lineal de complejas escenas bordadas, hasta el uso del bordado dentro de diferentes luchas políticas.

Un caso retratado por Hunter es el del movimiento de las sufragistas que estuvo marcado por la insurrección violenta, contradiciendo la idea de feminidad de la época, lo que costó la marginación, persecución y ridiculización de sus integrantes. Los carteles bordados -como gesto de la presencia femenina- se popularizaron en las marchas de mujeres sufragistas, eran cientos, tantos que respecto a la manifestación de 1908 Hunter lo describe como "un glorioso espectáculo visual que superó cualquier demostración de fuerza sindical. Fue un espectáculo teatral en una escala sin precedentes, elaboradamente ornamentado en un pronunciado espectáculo de feminidad deliberada" (Hunter, 2019, p. 123).

En 1974, según la investigación de Julia Bryan-Wilson en Fray: art and textile politics, existía una organización de mujeres con ideas feministas en Eugene, Oregon, que de manera humorística, nombraron a su agrupación "Ladies sewing circle and terrorist society" (Grupo de costura de damas y sociedad terrorista), lo que motivó a una de las participantes, Sally-Jo Bowman, a diseñar un logo como un patrón de bordado, el cual señalaba en la parte superior "Ladies sewing circle" con un motivo floral (algo típico en los motivos bordados de la época) y se deslizaba hacia la parte inferior con el remate "sociedad terro- 
rista”. Esta sátira feminista radica en cómo las “damas" relacionadas a la costura y las artes "decorosas" podrían llegar a incitar acciones ilegales y violentas.

En 1980, según Hunter, las protestas feministas estuvieron marcadas por la creación textil, lo cual demostraba visualmente la dualidad del mundo personal con la esfera pública. Por una parte, estaban los lienzos en grandes formatos conformados por creaciones colectivas sobre un mismo lienzo o sobre el ensamble de textiles pequeños que generaban una imagen extraordinaria de preocupación colectiva y por otra, las contribuciones personales de bordados u otras técnicas hechas a mano con temáticas que abogaban por campañas por cambio.

\section{Bordado y política: Las arpilleras chilenas}

Uno de los hitos en la creación del bordado vinculado a la política lo constituyen las arpilleras chilenas, abordado en amplios estudios de diverso tipo. En estudios de las últimas décadas a nivel global, se hace evidente el gran interés que posee el rubro por esta creación textil nacional. Desde papers como "Arpilleras: Chilean Culture of Resistance"(1984) de Moya-Raggio, "Agujas que hablan: las arpilleristas chilenas" (1985) de Marjorie Agosín o "Art against dictatorship: Making and exporting arpilleras under Pinochet" (2013) de J Adams; hasta libros recientes de autoras chilenas como "Arpilleras: hilván de memorias" (2019) de Catalina Larrere, y otros como "Where Memory Dwells: Culture and State Violence in Chile" (2008) de Macarena Gómez-Barris, a estos se suman muchas menciones en libros tales como Fray: art and textile politics (2017) de Julia Bryan-Wilson y Strange material: storytelling through textiles (2014) de Leanne Prain. Todos estos son sólo algunos ejemplos de investigaciones que abordan la temática, demostrando que las arpilleras han sido y seguirán siendo objetos de estudio que provocan una profunda fascinación. Las arpilleras son un tipo de bordado que es realizado sobre el material del mismo nombre, el cual solía ser utilizado para el embalaje de papas, harina u otros productos de uso cotidiano del hogar. La técnica de las arpilleras se caracteriza por el uso de retazos textiles y la unión de estos a través de técnicas de bordado como el punto festón, el cual genera una estética única e identitaria. Si bien la tradición de las arpilleras proviene de antes de las creadas durante la dictadura militar, fue el trabajo de Violeta Parra y las arpilleras de Isla Negra, elaboradas durante ese suceso temporal, lo que más ha motivado y nutrido a las diferentes investigaciones.

En 1974 comenzó la producción de arpilleras bajo el marco de un programa de ayuda de la Vicaría de la Solidaridad en apoyo a mujeres en estado de extrema pobreza, esto a causa del creciente desempleo y/o la desaparición o muerte de los sostenedores del hogar debido a la persecución política de la dictadura militar. El programa constaba de talleres de bordado en poblaciones marginales para que, con la venta de estas, las arpilleristas obtuvieron un sustento con el cual alimentarse. Las arpilleristas eran mujeres con edades que fluctuaban entre los 25 y 50 años, quienes se reunían en diferentes espacios como Puente Alto, La Pincoya, Lo Hermida y Villa O’Higgins. Allí las arpilleristas volcaron a través de los hilos sus testimonios más crudos acerca de su vida cotidiana, con diferentes retazos y lanas de colores bordaron la represión, la muerte, la pena y la rabia. Transformaron este espacio 
en un medio de denuncia y expresión. Las arpilleras eran anónimas, para evitar que las arpilleristas sufrieran persecución política, lo cual no fue efectivo en todos los casos. Sin embargo, estas arpilleras fueron vendidas en el extranjero, llevando más allá de la frontera las denuncias de sus creadoras.

\section{El diseño y el activismo visual}

La cultura del diseño trata de estructurar sistemas de encuentro entre lo visual y el mundo material, señala Julier (2006) cuando advierte que el estudio de la cultura del diseño permite comprender que la cultura no sólo se expresa como una pura representación o narrativa a través de la creación de artefactos para ser "usados" o "leídos" hacia un público pasivo/contemplativo.

Julier genera un framework para la investigación de la cultura de diseño a través de los conceptos de valor, circulación y práctica.

El primero se refiere al rol del diseñador como creador de valor, tanto en la creación de productos como en su argumentación. Es el trabajo de coordinar los procesos materiales e inmateriales, a través de los cuales la información cultural se filtra en una variedad de plataformas y momentos.

En segundo lugar, la circulación como una serie de elementos que sustentan y dan forma a las manifestaciones de la cultura del diseño, como la tecnología, contextos políticos, sociales y económicos y el factor humano. Los flujos de información y distribución dependen de los canales, formato, interrupción o facilitación para influencia movimientos y/o recepción a través de los sistemas de distribución.

Por último, la práctica tiene relación con el uso cotidiano, sobre las capas de información que llevan a los individuos a comprender y actuar de una manera determinada, donde diferentes prácticas están limitadas por reglas específicas. Por ende, las prácticas envuelven actividades cotidianas de la vida privada que son socialmente observables.

Esta noción acerca de la cultura del diseño, permite comprender la noción de cultura de diseño (design culture) hacia el diseño activista (design activism), suceso casi cronológico donde el diseño pasó desde ser un aliado y potenciador de la cultura neoliberal hacia el nacimiento de un movimiento que cuestiona y se opone al mismo.

Julier señala que la principal diferencia entre la concepción de la "cultura del diseño" y el "diseño activista" es que el primero es reactivo, es decir, se constituye como el resultado de acciones, mientras que el segundo es un movimiento consciente que busca la acción frente a un suceso que es politizado. Así, el diseño activista se vincula con otras prácticas como el diseño social, el diseño comunitario, el diseño participativo y el diseño crítico.

Markussen (2011) señalaba que esta acción del diseño activista no se refiere a un boicot, huelga, protesta, manifestación u otro acto político, sino que otorga su poder de resistencia de ser una manera diseñada (designerly) para intervenir en la vida de las personas. En ese sentido, se entiende que el diseño activista, por un lado, tiene un potencial político de disruptir y/o subvertir los sistemas existentes de poder y autoridad a través de su sensibilidad crítica de las maneras de vivir, trabajar y consumir; mientras que, por otro, posee 
un potencial estético en su habilidad de comprender la relación de los comportamientos y emociones de las personas. Markussen propone que el diseño activista posee la capacidad de que la relación entre lo que las personas hacen y sienten sea maleable a negociaciones. Cabe destacar la división entre el "diseño para la política" y el "diseño político", donde el primero se manifiesta cuando el propósito es apoyar y promocionar los mecanismos gubernamentales, mientras que el segundo se refiere a cuando el objeto o proceso de diseño activista es usado para crear "espacios de contestatarios". Así, el diseño político tiene la función de revelar, contestar y disentir (revelation, contest and dissensus) sobre estructuras y configuraciones existentes en la sociedad.

\section{Craftivism}

Si bien el feminismo de la segunda ola intentó marginar al bordado por ser un medio impuesto sobre la voluntad de la mujer y fue considerado como un símbolo de la opresión, hoy este medio se ha visto entusiastamente incorporado por el movimiento feminista como una forma de protesta política.

Uno de los términos que han nacido de este resurgimiento, es el de craftivism, que incorpora el "craft" (manualidad) con "activism" (activismo). Este término fue acuñado por Betsy Greer en 2003 al publicar un blog del mismo nombre: craftivism.com, lo cual luego se transformó en la publicación de su libro: "Craftivism: The Art of Craft and Activism", un compilado de varios relatos de artistas que han creado elementos hechos a mano como forma de protesta. Greer (2014) define el craftivism como un quiet activism, una manera de protestar desde una acción tranquila y ajena al ruido de las manifestaciones tradicionales (p. 10). Si bien el craftivism no concierne sólo al bordado, es una de las herramientas más utilizadas dentro de los artistas del libro, ya sea para la creación de colchas comunitarias, como el uso de cross stitch sobre diferentes formatos, en la creación de muñecos de tela, o en la elaboración de vestuario. Cabe destacar que en este libro también se encuentra el trabajo de las arpilleras chilenas, clasificado por ende, dentro del contexto del craftivism. Un par de años después, nace Craftivism Collective de manos de Sarah Corbett, quien, inspirada en Greer, inicia una campaña para "cambiar nuestro mundo una puntada a la vez" (Craftivism Collective, s.f.), eslogan que utiliza en su sitio. Corbett tiene una visión bastante alineada a Greer respecto a esta idea de manifestación tranquila, así hace evidente en su publicación "How To Be A Craftivist: the art of gentle protest" (2017), donde señala que este medio implica una persuación gentil, deliberadamente no violenta para motivar a otros a pensar y apoyar una variedad de causas para un mundo más justo y solidario. Más aún, en su sitio web señalan: "Si queremos que nuestro mundo sea más bello, amable y justo, ¿no debería nuestro activismo ser más bello, amable y justo?” (Craftivism Collective, s.f.) Lo cual se ve también reflejado en su manifiesto, donde el primer punto motiva a "Respirar, tomarlo con calma. El craftivism trata de adoptar un enfoque reflexivo para el activismo consciente" (Craftivism Collective, s.f.).

Algo particular del craftivism es que, al tratarse de un movimiento actual, no es ajeno al fenómeno de las redes sociales, y ha encontrado allí un espacio para la difusión tanto del movimiento como de las causas que apoyan las y los craft-activistas. Respecto a ello en una 
entrevista dentro del mismo sitio Greer señala que "la atención de las redes sociales depende de si un proyecto hace o no una de dos cosas: hace pensar a alguien o proporciona algo hermoso para mirar" (Craftivism Collective, s.f.), destacando con ello la función que debiera cumplir el craftivism para la popularidad y viralización en redes sociales, entendiendo esto como un medio para el apoyo de las diferentes causas.

Por otra parte, Julia Bryan-Wilson (2017) crítica este movimiento que, si bien visualiza la reivindicación del textil desde los 2000's, siendo "un modelo para pensar cómo los métodos artesanales se han codificado, implementado y politizado a lo largo del tiempo" (p.25), señala que el movimiento craftivism se ha vuelto una especie de guía hipster que se aleja de las ideas que impulsó The Subversive Stitch, volcándose hacia la comercialización de manuales y patrones más que a la divulgación de lo realmente DIY (movimientos Do It Yourself), que busca ser una respuesta en contra de los medios de producción masivos. Determina que el craftivism se ha vuelto un renovado kitsch más que un medio real de protesta.

La enajenación del movimiento llevado por el colectivo craftivism, puede provenir de sus enunciados que siempre tratan las causas de su activismo como si se tratase de un "otro". El craftivism "apoya" causas, así como invita a tomar con calma las luchas a las que se adhieren con tal de llegar de manera gentil a un público aún más ajeno a las mismas. Pero, ¿esta invitación no está alejando la práctica del craft de la vivencia misma de la rabia, la frustración y el sufrimiento que llevan consigo las injusticias en causas sociales, ecológicas y políticas? Pérez-Bustos, Tobar y Márquez (2016) explican como para el estudio etnográfico en el análisis de la práctica del bordado, era indisoluble la experiencia física para obtener conocimiento. Ellas se involucraron en el aprendizaje del bordado artesanal cartagüeño (Colombia), donde se acercaron a un grupo de bordadoras para aprender acerca de su técnica y su cotidianidad. Ante uno de los primeros encuentros solicitaron a una de las bordadoras que describiera cómo realizar un punto, a lo que ella respondió que no podía, que ella sabía hacerlo pero no explicarlo: "Su comentario sobre lo difícil que le queda explicarnos de manera racional lo que hace es casi una súplica para que no le pidamos palabras y que, en cambio, aprendamos con el cuerpo" (p. 11).

La relación del bordado con el cuerpo y su contexto es algo que profundizan durante este análisis etnográfico, donde señalan que el conocimiento proviene desde la interacción del cuerpo, con el mundo y las cosas que le habitan. El bordado es un medio que está estrictamente relacionado al cuerpo, tanto para su creación (costura como acción) como para la motivación de sus representaciones visuales, las cuales dependen de las historias, memorias y sentimientos de su ejecutora.

Es por ello que es interesante tomar en consideración que el Craftivism, como se ha llevado a través del tiempo en el colectivo de Greer, se ha despegado de la idea del crear con el cuerpo como una manifestación visceral y emocional detectada por Pérez-Bustos, Tobar y Márquez, llevándolo por un camino más pacífico y desconectado de su contexto. 


\section{Relato textil del estallido social en Chile de 2019}

El 18 de octubre de 2019, un grupo de estudiantes saltaban por los torniquetes del metro de Santiago de Chile manifestándose en contra del alza de tarifas, en treinta pesos chilenos, de este medio de transporte. Ese gesto determinaría el lema "no eran treinta pesos, eran treinta años", aludiendo a los años posteriores a la dictadura militar en Chile, en los cuales el sistema económico neoliberal construyó un sistema de grave desigualdad, cuyo descontento provocó el "estallido" social.

Lo que desató una explosión de protestas en distintos lugares de Santiago, concentrados mayoritariamente fuera de las estaciones de metro. Allí se realizaron diferentes expresiones de descontento tales como incendios, barricadas, saqueos, cacerolazos, y manifestaciones que fueron fuertemente reprimidas por parte de los carabineros, la fuerza policial militarizada chilena.

La vivencia de la represión durante estos hechos fue la que condujo a la experiencia creativa y proyectual del relato textil, día a día, de lo que fue aconteciendo entre los meses de octubre de 2019 y marzo del 2020, en medio de protestas, acuerdos, violaciones a los derechos humanos y la incertidumbre generalizada.

El objetivo general del proyecto, además de conformar parte de los elementos activos en la protesta social, fue la visibilización del bordado como registro visual histórico de momentos de crisis elaborado por mujeres, para la contribución de nuevas perspectivas de conocimiento en la comprensión de una historia de las mujeres que se nutra de su legado visual.

$\mathrm{Al}$ comprender el bordado como un artefacto portador de memorias subterráneas, que se desenvuelve en momentos de crisis fomentado por diferentes movimientos sociales, es que este proyecto nace y se desarrolla sincrónicamente con los sucesos acontecidos durante el estallido social ocurrido en Chile desde el 18 de octubre del 2019.

Así mismo, la segunda parte del proyecto busca llevar al espacio público las memorias portadas en los bordados, como hablamos anteriormente, producto de la pandemia se impulsó una transformación digital generalizada que también afectó al ámbito de las artes, diseño y cultura. Es por ello que, por una parte, los usuarios desarrollaron nuevas necesidades de consumo de entretenimiento y desarrollo personal debido a la cuarentena obligatoria que cambió radicalmente sus rutinas y costumbres, mientras que por otro los ámbitos culturales se convirtieron en herramientas para sobrellevar el confinamiento, ayudando a generar catarsis emocionales frente a los momentos difíciles que implica el estado de pandemia.

El académico y doctor Sergio Villena Fiengo (2020), actual director Instituto de Investigaciones Sociales de la Universidad de Costa Rica, al respecto señala que:

En cierto sentido y en los márgenes de la desigualdad social, esta crisis puede ser una oportunidad para prescindir de los placeres frívolos que nos ha impuesto la sociedad del consumo y del espectáculo, y para explorar (...) otros placeres, desarrollar otras habilidades, explorar y construir vínculos más gratificantes. El arte nos hace sentir, con nuestros diversos sentidos, que "otro (fin del) mundo es posible" también en estas circunstancias. 
Es por ello que se transforma la idea inicial de culminar el proyecto con una exhibición física, hacia la creación de un concepto que democratice el acceso al proyecto a través de una exhibición digital, la cual, para hacer referencia a los acontecimientos y siguiendo la idea de explicitar el bordado como registro de memoria, se ejecutará durante la conmemoración del primer aniversario desde el estallido social.

Así, el proyecto se ve marcado por dos instancias principales dictadas por su contexto temporal, social, político y de salubridad. La primera es la elaboración y publicación síncrona de bordados diarios en la red social Instagram que relatan y registran sucesos contingentes relacionados con el llamado "estallido social" desde octubre del 2019 y la segunda es el trabajo fotográfico y curatorial para la publicación de la exhibición virtual en contexto de pandemia provocada por el COVID-19 en octubre del 2020.

El proyecto tuvo como referentes principales: conceptuales, Conflict Textiles; funcionales, Insta novels de The New York Public Library, Museo Nacional del Prado, Second Canvas; y visuales en el bordado contemporáneo.

\section{Metodología proyectual}

Al determinar al bordado no sólo como un elemento de protesta sino, además, como un registro histórico que resguarda y porta memorias, se crearon bordados sobre sucesos relevantes contingentes con miras hacia la producción diaria, los cuales fueron compartidos a un público amplio a través de redes sociales públicas.

El proyecto se desarrolló en tres dimensiones:

1. Acontecimiento. La recopilación y validación de acontecimientos diarios relevantes.

Se realizó una observación de fuentes de información, determinadas por su viralización en redes sociales, visibles en Twitter a través de su sistema de trending topic; en Facebook, a partir de la cantidad de compartidos en medios de prensa oficiales o sitios alternativos; e Instagram, con la presencia del mismo en "IG Stories" e inclusive Whatsapp, a través de la presencia de "cadenas de mensajes" que se repetían en diferentes grupos. Y por la credibilidad del suceso, a través de la investigación de diversas fuentes oficiales tales como INDH, prensa tradicional escrita o RRSS estatales.

2. Relato visual. El registro diario de los acontecimientos a través del bordado.

El trabajo de definición de la visualidad y técnica fue dado por la experimentación a medida que se desarrollaba el proyecto, recordando que estos debían ser elaborados en un contexto contingente y lo suficientemente eficiente para no topar con otros sucesos relevantes. Así, la visualidad o estilo estuvo dado a partir de probar técnicas de diversos referentes, los cuales utilizaban estilos minimalistas y que enfocan los esfuerzos en la optimización de la velocidad de producción, sin perder la claridad del mensaje. En algunos casos, una vez determinado el suceso y la técnica, se procedió a seleccionar imágenes referenciales que apoyaran en el proceso de creación de la composición visual. Éstas fueron tomadas, en general, a partir de fotografías de prensa alternativa, quienes publicaban sus imágenes en redes sociales, quienes fueron citadas y etiquetados al momento de subir los bordados. 
3. Difusión. La creación de una bitácora digital. Difusión en otros medios.

Reacciones. La publicación de las fotografías de los bordados fue realizada en un perfil público utilizando hashtags, por lo que cualquier usuario podía ver, comentar y compartir. Todos estos indicativos son los utilizados para medir el impacto de una publicación en la red social Instagram.

Viralización. Los bordados viralizados no sólo representaban lo que estaba sucediendo en ese momento, sino que daban hincapié a la apertura de conversaciones y discusión.

Impacto en otros medios. Se realizó una nota sobre el proyecto en un periódico de circulación nacional. Y se realizó una Exhibición de los diseños textiles en contexto de huelga feminista 2020.

\section{Elaboración del bordado}

El proceso de planificación del diseño de cada bordado estuvo fuertemente definido por sus tiempos. Al tratarse de un proyecto que buscaba albergar una gran cantidad de situaciones, requería de un trabajo de diseño optimizado hacia la rapidez de la producción y claridad en la transmisión del mensaje. Para ello, fue necesario conocer los diferentes tipos de puntadas y su dificultad.

Las puntadas de bordado o puntos de bordado son los diferentes tipos de movimiento de la aguja utilizados en el bordado a mano, estas son las unidades más pequeñas al momento de ejecutar un bordado. La conjunción de estos generan patrones de bordado.

Los puntos y patrones de bordado se han divulgado a través de diversas fuentes, como el traspaso de técnicas familiares, el uso de revistas de bordado o a partir de tutoriales y cursos online. Aún así, existen puntos estándar que suelen encontrarse transversalmente en las diversas fuentes, entre ellas se encuentran los puntos recto, pespunte, cadeneta, tallo, nudo francés, festón, relleno y llano. Cada uno de estos puntos poseen su propia complejidad y tiempo de elaboración, los cuales se van afinando a partir del quehacer donde cada bordador/a plasma su propio ritmo y estilo.

A favor del proyecto, las puntadas más adecuadas eran las más rápidas de ejecutar y que entregarán resultados limpios y claros, lo cual llevó a la experimentación de varios patrones con puntadas mixtas según lo que deseaba tardar y demostrar en cada detalle dentro de la composición. Para tener una referencia de la diferencia en la velocidad entre puntos realizados, se realiza un muestrario (Figura 1) que detalla el tiempo necesario para confeccionar cada punto en un largo de $5 \mathrm{~cm}$.

Los bordados fueron realizados en su mayoría en un formato de $10 \mathrm{cms}$ de diámetro, lo cual permitía completar el espacio rápidamente (en especial al aplicar puntada de relleno). Gracias a que era cómodo para transportar, permitió poder realizar su elaboración en casi cualquier espacio (Figura 2), por lo que varios de estos fueron elaborados en el lugar de los hechos, no sólo como una guía visual de lo acontecido, sino para plasmar en los hilos el sentimiento colectivo que albergaban los espacios, en especial los de protestas en la llamada popularmente "Plaza de la Dignidad" (Figura 3), oficialmente Plaza Baquedano. 


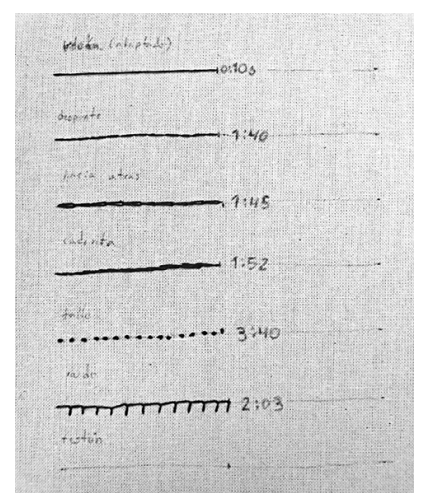

1
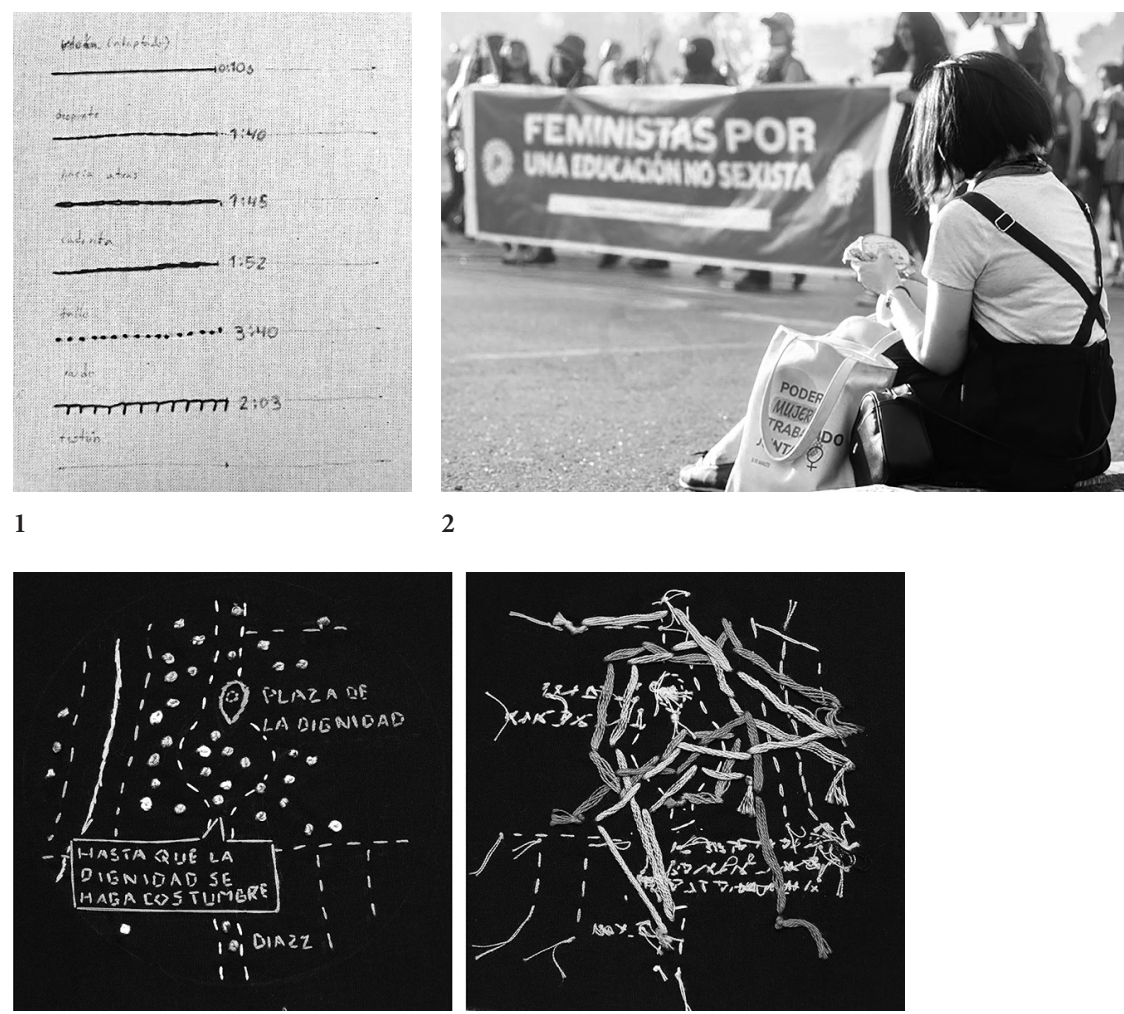

2

3

Figura 1. Muestrario del tiempo necesario para confeccionar cada punto en un largo de $5 \mathrm{~cm}$. Figura 2. Realización de bordado durante la manifestación en la "Plaza de la Dignidad” (Plaza Baquedano de Santiago de Chile). Figura 3. Derecho (izquierda) y revés (derecha) de bordado "Plaza de la Dignidad".

\section{Transformación digital. Publicación en redes sociales}

En principio el trabajo realizado con los bordados se pretendía convertir en una exhibición callejera; sin embargo, mientras se realizaba la planificación del mismo comenzó la crisis sanitaria producto del virus COVID-19.

En Chile, se declaró "estado de excepción constitucional de catástrofe" el 18 de marzo de 2020, luego de 15 días desde la confirmación del primer contagio por COVID-19 en el país. El estado de excepción traía consigo medidas de prevención para evitar o ralentizar la propagación del virus, como el cierre total de fronteras, cuarentena obligatoria para personas expuestas al virus y cordones sanitarios entre regiones. Todas estas medidas fue- 
ron resguardadas por las Fuerzas Armadas, quienes ya habían participado en un estado de excepción unos meses atrás producto del estallido social.

A partir del confinamiento y las recomendaciones de distancia social producto del covid-19, nos hicimos testigo y partícipe de un proceso de digitalización en muchas áreas de nuestra vida diaria. Necesidades básicas como conseguir alimentos, medicamentos o salud impulsaron a diferentes organizaciones a crear o mejorar sus soluciones digitales para solventar las necesidades de las personas. Este proceso es conocido en las industrias TI (tecnología de la información) como transformación digital que consiste en el proceso de integración de la tecnología digital en todos los ámbitos de la sociedad y los resultados de ésta (Kaplan \& Haenlein, 2019).

Más allá de las necesidades básicas e imprescindibles, también nacieron muchas iniciativas culturales y de dispersión para ayudar a aliviar el estrés provocado por vivir una situación de crisis sanitaria, así como encontrar nuevas fuentes de ingresos para las personas que trabajan en industrias creativas.

\section{Creación de relato digital. Diseño de feed}

$\mathrm{Al}$ año de realizar los bordados, compartidos en redes sociales, se propone una exhibición digital de los bordados para conmemorar el primer aniversario desde los sucesos, considerando el contexto de confinamiento producto de la pandemia del COVID-19 y su extensa duración.

Dentro del contexto de la pandemia, se procedió a configurar el relato textil en formato digital. Los bordados fueron fotografiados de modo de cautelar no solo su forma (ilustrativa, textual o iconográfica), sino también su técnica, tanto a nivel de elección de puntadas, por la materialidad fruto del contraste entre la tela y los hilos de bordar, como por la inclusión de otros objetos como mostacillas u otros (Figura 4). Dado que es esta textura propia del trabajo de bordar, lo que la diferencia de otras imágenes como las ilustraciones o diseños digitales. Es por eso que uno de los principales desafíos al tomar las fotografías fue capturar y transmitir esta textura.
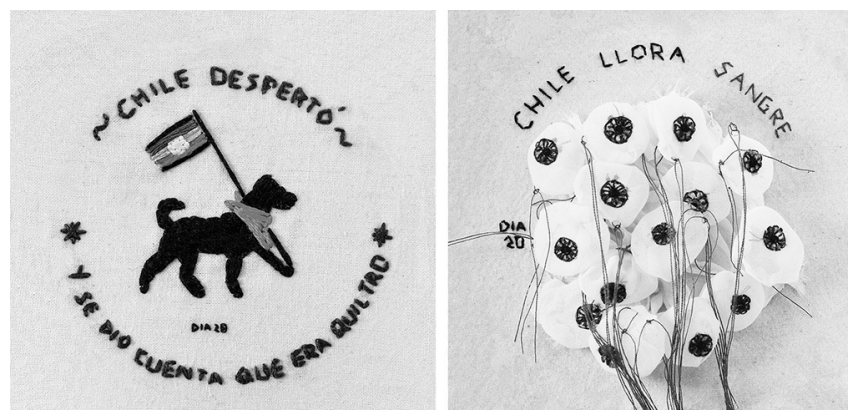

Figura 4. Fotografía y digitalización de bordado. 
Las fotografías fueron exhibidas en la plataforma Instagram, la que se reconoce por su uso masivo como herramienta de posicionamiento de marca, tanto comercial como individual. Una de las tendencias más exploradas fue la preocupación por el diseño del feed, el cual se conforma por la visualización de las imágenes subidas por un mismo usuario a la plataforma, que son almacenadas en una galería cuadriculada con 3 de imágenes de ancho, ordenadas en orden cronológico de publicación.

Se han observado tendencias que buscan priorizar un solo tipo de visualidad en todo el feed, ya sean imágenes con preponderancia tipográfica o la publicación exclusiva de videos. En nuestro caso, una vez mapeados los recursos existentes y levantadas las funcionalidades de la plataforma, fue necesario encontrar cómo era posible acomodar las fotografías de manera que se generase un relato. La funcionalidad más adecuada para ello fue la publicación dentro del feed del usuario, este modo de subida permite imágenes estáticas, audiovisuales y descripciones de texto, además de que permanecen por tiempo indefinido dentro del perfil, lo que permitiría al usuario visitarlo cuantas veces desee y, así mismo, es una de las funcionalidades más flexibles, puesto que las imágenes pueden ser vistas desde diferentes pantallas, como el feed, la búsqueda general, ser enviados por mensaje directo y ser compartidas en historias.

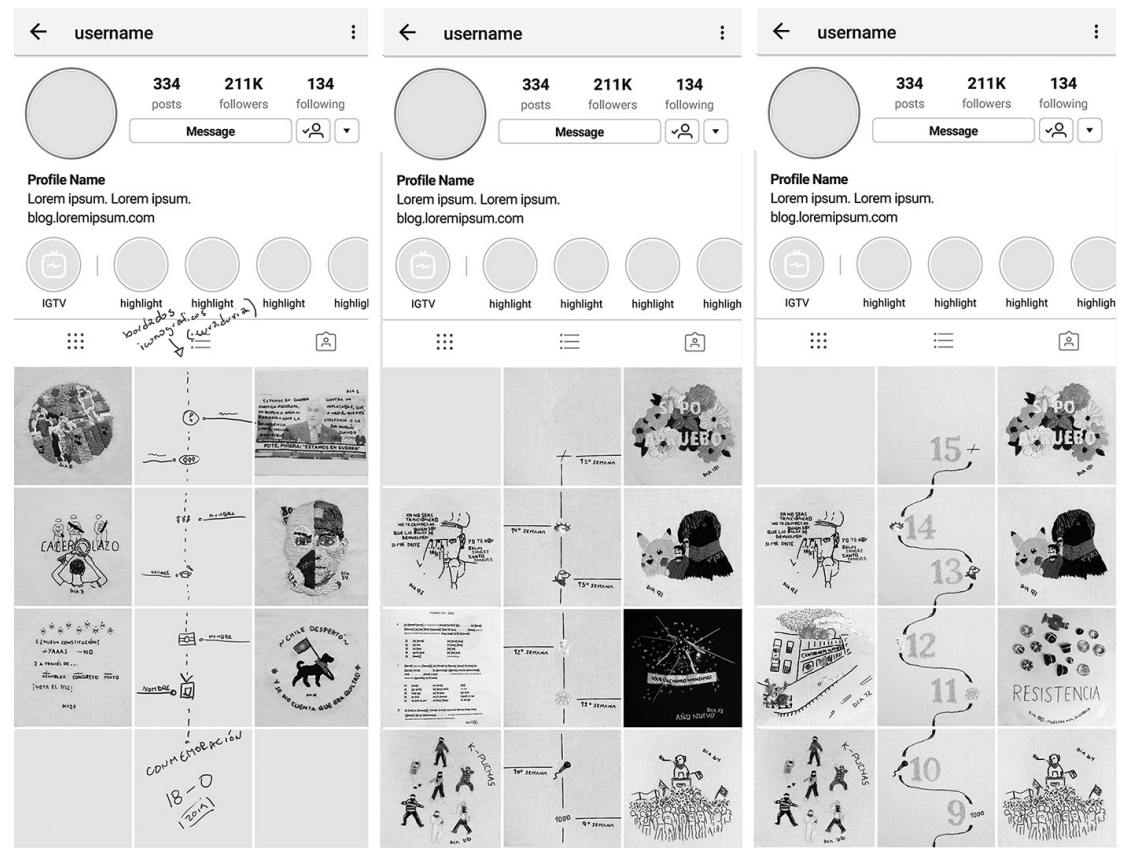

Figura 5. Maqueta de configuraciones de feed de Instagram. 
Para la formulación del relato (Figura 5) se identificaron 3 diferentes maneras de leer las imágenes subidas al feed de Instagram:

1. Inicio: Es la primera pantalla que ve el usuario al ingresar a la aplicación, aquí aparecen todas las publicaciones realizadas por los perfiles y hashtags que sigue el usuario, el cual además es un espacio utilizado para anuncios publicitarios. Las publicaciones son ordenadas desde la más recientemente publicada a la más antigua. Su dirección de lectura está condicionado por el scroll vertical, permitiendo al usuario ver imágenes a ancho completo.

2. Feed: Este aparece una vez el usuario ingresa a su perfil o al de otro usuario. En la parte superior aparece información sobre el usuario, seguido por sus historias destacadas y el menú de opciones por tipo de publicación, donde puede aparecer IGTV, Reels, Filtros y Etiquetas, en caso de que existan. Luego viene el feed de las imágenes publicadas por ese usuario, en particular, estas aparecen ordenadas en 3 columnas con dirección de lectura en forma de zeta y que determina el orden desde la más reciente (más arriba a la izquierda) a la más antigua (más abajo a la derecha). Esta cuadrícula permite al usuario tener una visión general de las imágenes donde puede ir recorriéndolas visualmente de manera dispersa y permite tener una visión global de la visualidad utilizada en el perfil.

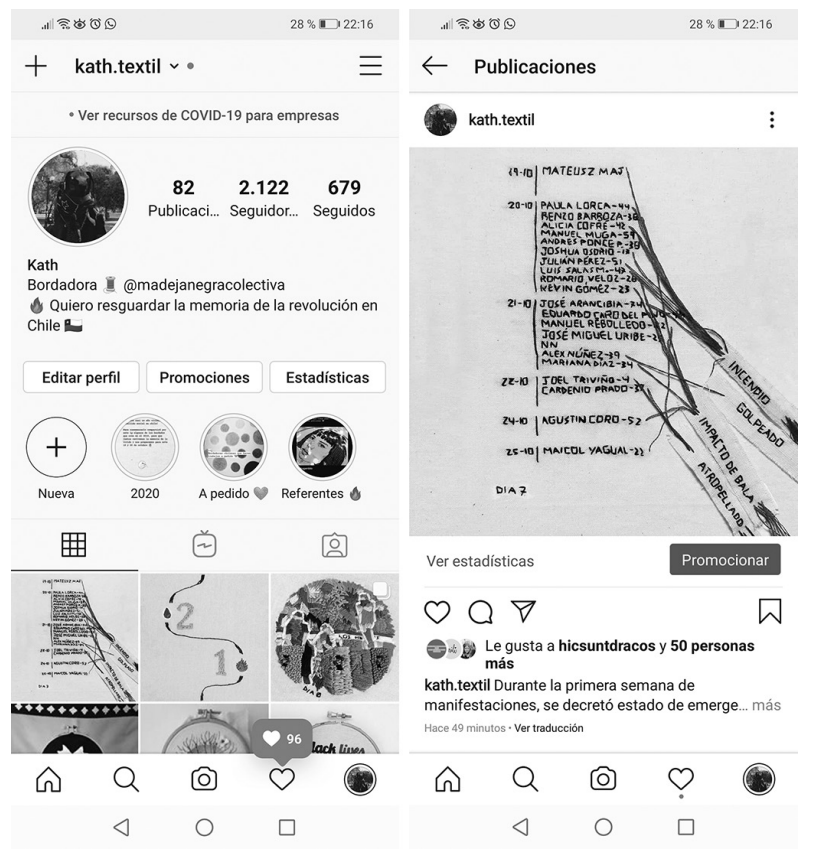

Figura 6. Publicación y recepción de los bordados en la plataforma Instagram. 
3. Publicaciones del usuario: Una vez el usuario presiona una imagen del feed, esta imagen se visualiza en ancho completo, y el usuario puede hacer scroll vertical para seguir visualizando otras publicaciones. El orden es de arriba hacia abajo, desde la más reciente a la más antigua, respectivamente.

La elección de la composición fue a partir de variadas maquetas con posibles lecturas, considerando como principal el feed de Instagram.

Una vez completada la etapa de experimentación de composiciones, se evaluó cada una según cómo impactarían en las diferentes pantallas. Dado el alto volumen de bordados, se optó por seleccionar los bordados que fuesen muy representativos y que hubieran tenido buena recepción en el inicio del proyecto (Figura 6), los que serían agrupados por publicación como "semanas" desde el inicio del estallido social, así mismo, se pondría un límite de 15 semanas, las cuales son las más robustas en cuanto al contenido disponible, esto redujo la cantidad de publicaciones a 24 (Figura 7).

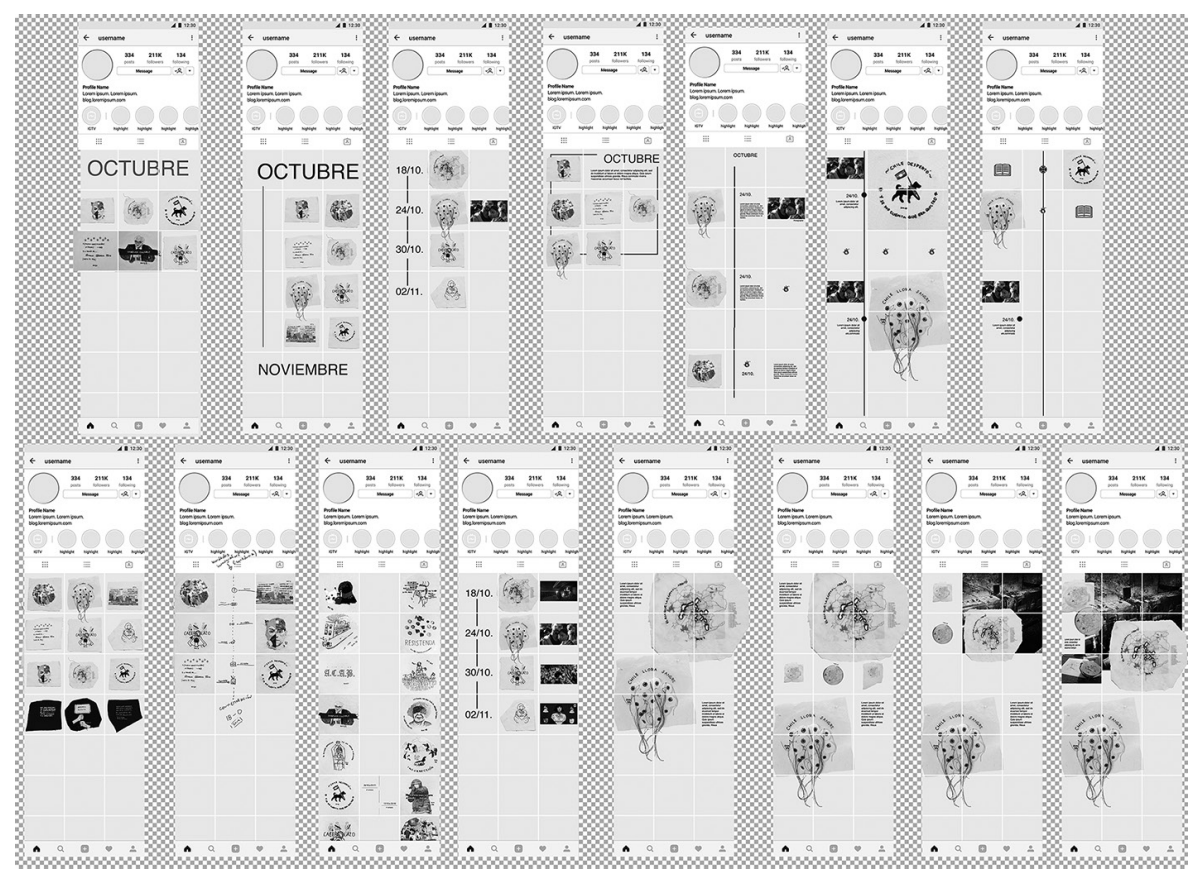

Figura 7. Conformación del relato en la plataforma de Instagram. 


\section{Conclusiones}

La capacidad de adaptación de las y los diseñadores a contextos complejos, desde una mirada creativa y crítica, es el principal aspecto desarrollado en este proyecto. No solo se desarrolla la actividad metodológica proyectual, sino que, además, se desarrolla una vinculación viva con el entorno social. Siendo reconocido y compartido.

El uso del bordado como un instrumento de protesta se revela como un quehacer de mujeres feministas, que desde el condicionamiento doméstico de su tradición histórica se recoge en el activismo social y las dinámicas de las redes sociales. Como lo fue el histórico momento del estallido social chileno $18 \mathrm{O}$ (18 de octubre). Se transforma en un registro histórico afectado de la experiencia, emocionalidades que transcurrieron en una sincronía de sucesos que marcaron el devenir social de Chile.

Así, la creación textil retoma un nuevo énfasis relacionado a la protesta política, que se suma a las arpilleras, que marcaron un precedente que sigue a flor de piel en las conversaciones entre bordadoras. Es una gran oportunidad para el diseño, puesto que puede y debe hacerse cargo de visibilizar y resguardar esta herencia y patrimonio cultural visual. De la misma manera, el área de la creación textil (en específico el bordado) sigue siendo un dominio predominantemente femenino, por lo que su legado visual se constituye un portador de memorias capaz de aportar nuevas visiones a la historia, de mano de las mujeres. Más aún, es relevante cuestionar qué tanto podría significar para la disciplina del diseño integrar este legado visual dentro de su conocimiento histórico. ¿Implicaría una inclusión y valoración de más diseñadoras dentro de lo que entendemos por historia del diseño?, ¿Cómo eso impactaría en el desarrollo de las nuevas generaciones de diseñadoras?, ¿Podría esto aportar a dejar de considerar el bordado como un "arte menor" o "artesanía de consumo"? Todas estas son algunas de las preguntas que se desprenden de la experiencia completa de este proyecto.

Este proyecto fue elaborado desde una perspectiva individual, así como desde una posición política específica, puesto que la memoria no puede ser despegada de la interpretación de la realidad propia, por lo que, es posible proyectar a otras manos creadoras y otras memorias subterráneas, de manera que la visión se amplíe y diversifique. Esto puede ser dado a través de proyectos de bordado colectivo, exhibiciones digitales colaborativas $\mathrm{u}$ otras instancias donde se fomente el devenir colectivo en búsqueda de motivar a más mujeres a reconocer su herencia visual traspasada a través de las generaciones a partir de la creación textil. Así mismo, este proyecto albergó principalmente el bordado como medio textil, por lo que se establece una oportunidad de diversificar la línea de investigación hacia otras materialidades y/o técnicas, tales como la tapicería, el tejido de cintura, la orfebrería, la creación de colchas, $\mathrm{u}$ otros.

\section{Referencias bibliográficas}

Adams, J. (2013). Art against Dictatorship: Producing and Exporting Arpilleras under Pinochet. University of Texas Press. 
Agosín, M. (1985). Agujas que hablan: Las arpilleristas chilenas. Revista Iberoamericana, 51(1), 523-529. https://doi.org/10.5195/reviberoamer.1985.4066

Bryan-Wilson, J. (2017). Fray: art and textile politics. The University of Chicago Press.

Corbett S. (2017). How To Be A Craftivist: the art of gentle protest. Unbound.

Gómez-Barris, M. (2008). Where Memory Dwells: Culture and State Violence in Chile. University of California Press.

Greer, B. (2014). Craftivism: The Art of Craft and Activism. Arsenal Pulp Press.

Greer, B. (s.f). Craftivism Collective. https://craftivist-collective.com/

Heidegger, M. (1980). Die Ursprung des Kunstwerkes, Holzwege. Vittorio Klosterman.

Hunter, C. (2019). Threads of Life. A history of the world through the eye of a needle. Sceptre.

Isava, L. (2009). Breve introducción a los artefactos culturales. Estudios 17(1), 441-454. Recuperado de: https://biblat.unam.mx/es/revista/estudios-revista-de-investigaciones-li terarias-y-culturales/articulo/breve-introduccion-a-los-artefactos-culturales

Julier, G. (2006). From Visual Culture to Design Culture. Design Issues: 22(1), 64-76. https:// doi.org/10.1162/074793606775247817

Julier, G. (2013). From Design Culture to Design Activism. Design and Culture, 5(2), 215 236. https://doi.org/10.2752/175470813X13638640370814

Larrere, C. (2019). Arpilleras: hilván de memorias. Ocho Libros.

Lifschitz, J. A. \& Arenas, S. P. (2012). Memoria política y artefactos culturales. Estudios Políticos, (40), 98-119. Instituto de Estudios Políticos. Recuperado de https://revistas. udea.edu.co/index.php/estudiospoliticos/article/view/13205

Markussen, T. (2011). The disruptive aesthetics of design activism: enacting design between art and politics. Nordic Design Research Conference 2011, Helsinki. Recuperado de: https:// archive.nordes.org/index.php/n13/article/view/102

Moya-Raggio, E. (1984). Arpilleras: Chilean Culture of Resistance. Feminist Studies, 10(2), 277. https://doi.org/10.2307/3177867

Nochlin, L. (2018). Why Have There Been No Great Women Artists? En Women, Art, and Power and Other Essays, pp. 145-178. Routledge.

Parker, R. (1984). The subversive Stitches: embroidery and the making of the feminine. Women's Press.

Pérez-Bustos, T. \& Piraquive, A. C. (2018). Bordando una etnografía: Sobre cómo el bordar colectivo afecta la intimidad etnográfica. Debate Feminista, 56. https://doi.org/10.22201/ cieg.2594066xe.2018.56.01

Pérez-Bustos, T.; Tobar-Roa, V. \& Márquez-Gutiérrez S. (2016). Etnografías de los contactos. Reflexiones feministas sobre el bordado como conocimiento Antípoda Revista de Antropología y Arqueología. 26(47). https://doi.org/10.7440/antipoda26.2016.02

Pollak, M. (2006). Memoria, olvido, silencio. La producción social de identidades frente a situaciones limites. Ediciones al Margen.

Prain, L. (2014). Strange Material: Storytelling through Textiles. Arsenal Pulp Press.

Villena, S. (13 de mayo de 2020). Pandemia del Coronavirus y sus repercusiones en las manifestaciones culturales. FACSO. Universidad de Chile. Recuperado de: http://www.facso.uchile. cl/noticias/163375/coronavirus-y-sus-repercusiones-en-las-manifestaciones-culturales 
Abstract: This article presents embroidery as a feminine cultural artifact, understanding that embroidery, conceived as a minor feminine activity, has been transforming and can be a political act, for activism and memory. This is where design can be articulated as an actor whose experience becomes experiential as well as a producer of artifacts of use.

The theoretical review, the project of a textile story made in the context of the so-called Chilean social outburst occurred in October 2019 is framed.

The project constitutes a log through embroideries made during the period of October 2019 and March 2020, to be exhibited on digital platforms.

Keywords: Embroidery - culture - design - memories - women - politics.

Resumo: Este artigo apresenta o bordado como um artefato cultural feminino, entendendo que ele é concebido como uma atividade feminina menor que se transformou, podendo se tornar um discurso político de ativismo e memória. O design torna-se assim tanto um ator cuja experiência é transformada em algo experiencial quanto um produtor de artefatos de uso. Por meio da revisão teórica, é enquadrado o projeto de uma história têxtil realizada no contexto da chamada eclosão social chilena ocorrida em outubro de 2019. O projeto constitui um blog através do bordado elaborado durante o período de outubro de 2019 e março de 2020, para ser exibido em plataformas digitais.

Palavras chave: bordado - cultura - design - artefatos de memória - mulheres - política.

[Las traducciones de los abstracts fueron supervisadas por el autor de cada artículo] 